\title{
Growth impacts of Swiss steering-based climate policies
}

\author{
Adriana Marcucci ${ }^{*}$ (I) and Lin Zhang ${ }^{2}$
}

\begin{abstract}
This paper studies the growth impacts of realizing two long-term carbon targets in Switzerland (reducing $\mathrm{CO}_{2}$ emissions in 2050 by $72 \%$ and $80 \%$ relative to 1990 levels) with alternative steering-based climate policies that include a uniform tax on the whole economy and differentiated tax schemes. For this analysis, we use the Computable Induced Technical change and Energy (CITE) model, a computable general equilibrium (CGE) model with endogenous growth. We find that achieving the climate targets could lead to a slight decrease in utility and an increase in investments through the shift of labor from manufacturing to research. Higher investments coming from higher innovation could compensate the reduction in output due to the carbon policies, leading to relatively unaffected economic output. The economic structure adjusts following three drivers: energy intensity, substitutability from energy in the production of the intermediate varieties, and the relative attractiveness of research. Moreover, the results from the CITE model show that the economy-wide carbon tax is the most effective option when we consider the effects on utility. Differentiating the sectors regulated by the emission trading system (ETS) has relatively low impact while applying lower taxes on transport fuels results in lower utility driven by inefficiencies in the sectoral mitigation efforts. Finally, we find that the effects of increasing the stringency of the target (in terms of foregone utility) are independent from the policy instrument.
\end{abstract}

Keywords: Endogenous growth, Swiss climate policy, CGE, Differentiated taxes

\section{Introduction}

The Paris Agreement is a voluntary international agreement intended to mitigate climate change globally. Countries involved in the agreement have committed to different short-term targets in the Nationally Determined Contributions to the UNFCC. Now, countries face the challenge of deciding on the stringency of their longterm commitments and the policies through which such commitments would be achieved. In deciding on their mitigation targets and strategies, countries must take macro-economic side effects into account. Such effects include, among others, economic growth, capital intensity, and market structures. In this paper, we investigate possible effects on the Swiss economy of alternative longterm targets and policy settings to reach those targets using a numerical modeling approach. By comparing targets with different stringencies and alternative carbon

\footnotetext{
*Correspondence: madriana@ethz.ch

${ }^{1}$ ETH Zurich, Center of Economic Research, 8092 Zurich, Switzerland Full list of author information is available at the end of the article
}

taxes, we shed light on the additional economic impactin terms of foregone utility from consumption and structural changes-of increasing the stringency of Swiss commitments to the Paris Agreement and the effectiveness of different policies.

Switzerland is an interesting case study since it is a small open economy with ambitious climate change mitigation goals. The Swiss 2050 Energy Strategy aims at reducing greenhouse gas (GHG) emissions and energy consumption as well as increasing the use of renewable-based energy sources while also phasing out nuclear power. The long-term goal of the Swiss Federal Council is to reduce GHG emissions to 1-2 tonnes of $\mathrm{CO}_{2}$ per capita in 2050 from around 6 tonnes of $\mathrm{CO}_{2}$ per capita today. Using a Computational General Equilibrium (CGE) model, we analyze the economic effects of meeting two targets consistent with these goals: 1.5 and 1.0 tonnes $\mathrm{CO}_{2}$ per capita for 2050.

The Swiss Federal Government is changing its climate and energy policy approach, from subsidies for renewable energy and energy efficiency measures moving towards 
steering-based policies. By using steering-based policies, the Swiss Federal Government provides consumers and producers with price signals that incentivize them to comply with carbon abatement goals (Swiss Federal Council, 2015a, b). We simulate three alternative steering-based policies that include (1) a uniform carbon tax in the economy, (2) differentiated taxes for the sectors regulated by the emission trading system (ETS) and non-ETS sectors, and (3) further differentiating the non-ETS sectors between heating and transport fuels. From an economic theory perspective, the first policy (a uniform tax) should lead to the lowest costs of achieving the climate target. However, distortions in the economy can explain the need for tax differentiation: international cooperation and spillovers, carbon leakage, tax interaction with pre-existing taxes, and social equity aspects. In the same way, real-world policy proposals hardly ever consider a uniform carbon price on the economy. For instance, a carbon price through a cap on ETS emissions (where the energy-intensive sectors are included) is used in many countries/regions, such as the EU, China, New Zealand, South Korea, some US states, and Quebec. Thus, the second instrument we evaluate in this paper is a differentiated carbon price between ETS and non-ETS sectors, which is in line with EU policies and allows for future harmonization of the EU and Swiss climate policy. Finally, in Switzerland, the carbon tax on transport fuels is lower than that on other fuels. A possible reason for this deviation from the uniform economy-wide tax is the interaction with high pre-existing taxes. High pre-existing taxes on transport fuels mean that Swiss use fewer transport fuels even before introducing more carbon taxes. This implies that some mitigation is already taking place and additional abatement efforts would imply higher costs. Hence, the last carbon policy scheme analyzed in this paper is a further differentiation of non-ETS sectors between heating and transport fuels. We evaluate the impact of differentiating carbon taxes on the efficiency of the policies in terms of economic growth.

To conduct our analysis, we use the CITE (Computable Induced Technical change and Energy) model, a multisectoral dynamic CGE model of Switzerland with fully endogenous growth (Bretschger et al. 2011; Romer 1990). In the model, purposeful investments in research and development $(R \& D)$ increase the number of varieties of intermediate inputs and the stock of knowledge, which supports growth by raising productivity. The CITE model is an appropriate tool to analyze the growth impact of alternative climate policies given its ability to endogenously determine R\&D decisions. This feature allows the model to differentiate potentially opposing effects from carbon policies: negative effects on the production of intermediates but also structural changes and increases in R\&D labor that sustain research and development, which can boost economic growth. These opportunities, however, are not exploited without modeling knowledge spillovers.

Overall, we find that reducing per capita emissions in Switzerland from 2.8 to 1.5 or 1.0 tonnes $\mathrm{CO}_{2}$ per capita-regardless of the policy pathway-implies moderate costs to the economy reflected in a slight reduction in consumption. Nevertheless, these effects are compensated with sectoral shifts and increases in investments that have positive effects on the economy. Moreover, our results show that the choice of policy instrument affects the costs of achieving the climate policies and that differentiating sectors increases mitigation costs. Importantly, we find that the effects of increasing the stringency of the target are independent from the policy instrument.

Our simulation results show that reducing emissions, in the text-book case of using an economy-wide uniform tax, implies lower total consumption but positive effects on investments and a relatively unaffected economic output. The yearly growth rate of consumption decreases by -0.21 and -0.28 p.p while that of investment increases by +0.46 and +0.55 p.p. (for the 1.5 and $1.0 \mathrm{tCO}_{2}$ p.c. target, respectively). The larger investment that foster economic output is achieved through the endogenous growth mechanism and changes in the structure of the economy. The sectoral changes follow the interplay of three factors: relative energy intensity of the sectors, substitutability from energy in the production of the intermediate varieties, and the relative attractiveness of research. While the first two effects are present in virtually all CGE models, the third one arises from the endogenous growth and implies larger investments due to shift of labor from manufacturing to research.

The economy-wide carbon tax is the most effective option when we consider the effects on utility. Differentiating ETS sectors has relatively low impact while applying lower taxes on transport fuels results in lower utility driven by inefficiencies in the sectoral mitigation efforts. The differences between the two carbon tax alternatives are given by two factors: (1) the changes in carbon price in the differentiated tax-decided a priori in the policy setup-and (2) the importance in terms of emissions of the differentiated sectors.

Our paper relates to two strands of the literature and is a part of a major Swiss research project: the Swiss Energy Modelling Platform (SEMP). First, we contribute to papers analyzing the efficiency of tax differentiation, and second, we add to analyses on Swiss climate policy. Several papers have analyzed the efficiency of tax differentiation using theoretical and numerical models, see for instance Hoel (1996), Markusen (1975), Böhringer et al. (2014), Boeters (2014), Landis et al. (2018), and Abrell et al. (2018). This paper complements these analyses by using a numerical 
model with endogenous growth that represents the positive impacts from climate policies on the economy driven by the endogenously determined R\&D. Different studies using numerical models have evaluated the realization of different carbon reduction goals in Switzerland, see for instance Marcucci and Turton (2012); Sceia et al. (2012); Böhringer and Müller (2014); Kannan and Turton (2016); Bretschger and Zhang (2017b); Karydas and Zhang (2017); Landis et al. (2018). This paper is part of the Special Issue of SEMP (Landis et al. 2019). The SEMP exercise aims at giving coherent and complementary answers to the options for reaching Switzerland's climate policy targets for 2050, by running and comparing several models that use synchronized assumptions and policy scenarios. Our contribution focuses on the macro-economic impacts and other aspects are analyzed in the rest of the Special Issue: distribution effects, the transport sector, and differences across models.

This paper is organized as follows: Section 2 describes the CITE model and the scenarios that we analyze in the paper, Section 3 presents and discusses the results of the SEMP scenarios, and Section 4 concludes.

\section{Methodology}

We analyze the growth effect of alternative Swiss emission targets for 2050 using different carbon pricing options including economy-wide uniform carbon taxes, differentiating ETS and non-ETS sectors, and further differentiating the non-ETS sectors between transport and heating fuels. For this analysis, we use the CITE (Computable Induced Technical change and Energy) model, a framework that includes Swiss energy-economic details in a general equilibrium model for the quantitative analysis of climate change mitigation and environmental policies.

\subsection{The CITE model}

The CITE model is a multi-sectoral CGE model with fully endogenous growth. It was originally developed by Bretschger et al. (2011) based on the so-called "new growth theory" from Romer (1990). Growth in the different sectors is driven by an expansion in the types of intermediate goods (machines). Investments in physical capital and knowledge extend the number of capital varieties, which fosters factor productivity.

\subsubsection{Firms and the endogenous growth mechanism}

The CITE model represents different sectors of the economy including ten non-energy sectors, three fossil energy sectors, and one electricity sector ${ }^{1}$. The market of the

${ }^{1}$ Non-energy sectors: agriculture (agr), chemical industry (chm), machinery (mch), construction (con), transport (trn), banking and financial services (bnk), insurances (ins), health (hea), other services (ose), and other industries (oin). Energy sectors: refined oil (oil), natural gas (gas), heat (het), and electricity (ele). final goods in these sectors is assumed to be perfectly competitive. The production technology is modeled by a constant elasticity of substitution (CES) production function that varies between the energy and non-energy sectors.

In the non-energy sectors, goods $Y_{i}$ in each sector $i$ are produced using a sector-specific intermediate composite $Q_{i}$ and a bundle of inputs from other sectors $B_{i}$ (as shown in Fig. 1); thus,

$$
Y_{i}=\left[\alpha_{i}{Q_{i}}^{\frac{\sigma_{Y, i}-1}{\sigma_{Y, i}}}+\left(1-\alpha_{i}\right) B_{i}{ }^{\frac{\sigma_{Y, i}-1}{\sigma_{Y, i}}}\right]^{\frac{\sigma_{Y, i}}{\sigma_{Y, i}-1}},
$$

where $\alpha_{i}$ is the share parameter and $\sigma_{Y, i}$ is the elasticity of substitution between $Q_{i}$ and $B_{i}{ }^{2}$ (Table 1 presents the values and references of all the parameters in the CITE model).

The endogenous sectoral growth mechanism is modeled through the increase in varieties of intermediate goods $\left(x_{i, j}\right)$. Innovators have profit incentives to create new varieties of these intermediate goods resulting in the growth of the sector. The different varieties constitute the intermediate composite $\left(Q_{i}\right)$ following a Dixit-Stiglitz CES function; thus,

$$
Q_{i}=\left[\int_{j=1}^{J_{i}} x_{i, j}^{\kappa} d j\right]^{1 / \kappa}
$$

where $J_{i}$ is the number available varieties of intermediate goods in sector $i$ and the mark-up parameter $\kappa$ is given by $\kappa=\left(\sigma_{Q}-1\right) / \sigma_{Q}$, where $\sigma_{Q}>$ 1 is the elasticity of substitution between the intermediates (see Table 1). Since intermediate goods are imperfect substitutes, there is monopolistic competition among producers of intermediate goods, with a mark-up factor $1 / \kappa$ over the marginal cost of production. Given the mark-up factor $(1 / \kappa)$, the share of revenues in the production of the intermediate composite $Q$ is given by $1-\kappa . \kappa$ also measures the gains from diversification, i.e., the productivity increase of the economy when using a larger variety of intermediate goods.

In each sector, intermediate firms produce the $j$ th intermediate good using labor $(L)$, energy $(E)$, and noncumulative capital $(V)$, assuming a CES production function,

$x_{i, j}=\left[\phi_{i, j} L_{i, j}^{\frac{\epsilon_{i}-1}{\epsilon_{i}}}+\zeta_{i, j} E_{i, j}^{\frac{\epsilon_{i}-1}{\epsilon_{i}}}+\left(1-\phi_{i, j}-\zeta_{i, j}\right) V_{i, j}^{\frac{\epsilon_{i}-1}{\epsilon_{i}}}\right]^{\frac{\epsilon_{i}}{\epsilon_{i}-1}}$

where $\phi_{i, j}$ and $\zeta_{i, j}$ are the share parameters and $\epsilon_{i}$ is the sector-specific elasticity of substitution.

${ }^{2}$ We omit time subscripts whenever there are no ambiguities. 


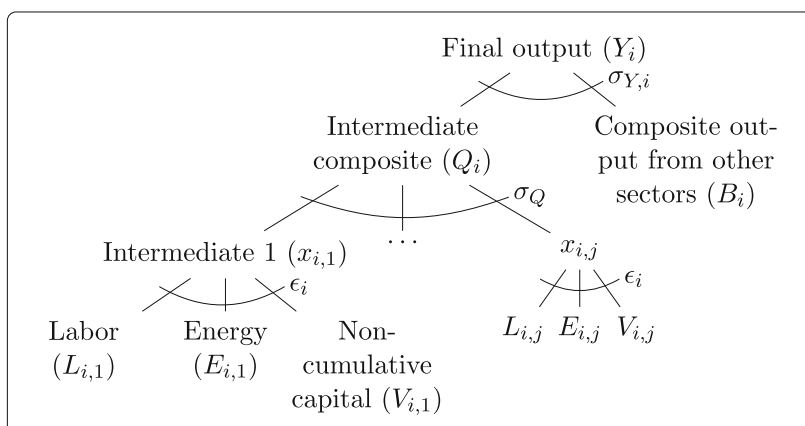

Fig. 1 Nested production function of regular sector $i$

\subsubsection{Physical investments and knowledge}

When a new variety of intermediate $\operatorname{good}\left(x_{i, j}\right)$ is produced, it is associated to a "blueprint" or "patent." These patents constitute the non-physical investments (knowledge, $\left.I_{K, i}\right)$. Firms are the owners of the patents, which together with the physical investments $\left(I_{P, i}\right)$, constitute the firm value (see Fig. 2).

The stock of varieties $J_{i}$ (introduced in Eq. 2) in the period $t+1$ is given by

$$
J_{i, t+1}=\left[\gamma_{i} I_{P i, t}^{\frac{\tau-1}{\tau}}+\left(1-\gamma_{i}\right) I_{K i, t}^{\frac{\tau-1}{\tau}}\right]^{\frac{\tau}{\tau-1}}+\left(1-d_{t}\right) J_{i, t},
$$

where $\gamma$ is the share parameter, $\tau$ is the elasticity of substitution between physical and non-physical investments, and $d_{t}$ is the depreciation. This is the so-called law of motion of capital in the model. The incentives to invest in new varieties come from the monopoly rent that results from the production of intermediates.

We assume that knowledge is produced using labor in research and other specific inputs used in the research labs, considered substitutes. Research efforts are supported by positive learning spillovers that are proportional to the number of already developed varieties. Accordingly,

Table 1 Elasticities of substitution used in the model

\begin{tabular}{|c|c|c|c|}
\hline & Nesting & Value & Reference \\
\hline$\sigma_{Y, i}$ & $Q_{i}$ and $B_{i}$ in final goods & $\begin{array}{l}0.392 \text { (agr); } 0.848 \text { (chm, oil, gas); } \\
0.518 \text { (mch); } 0.1 \text { (ele); } 1.264 \text { (con); } \\
0.352 \text { (trn); } 0.568 \text { (oin); } 0.492 \text { (other } \\
\text { sectors) }\end{array}$ & Okagawa and Ban (2008) \\
\hline$\kappa$ & $\begin{array}{l}\text { Measures level of } \\
\text { substitution between } x_{i j} \text { in } \\
\text { intermediate composite }\end{array}$ & 0.75 & Bretschger et al. (2011) \\
\hline$\epsilon$ & $\begin{array}{l}L_{i, j}, E_{i, j} \text { and } V_{i, j} \text { in } \\
\text { intermediate goods }\end{array}$ & $\begin{array}{l}0.7 \text { (agr, oil, gas, het); } 0.52 \text { (con, oin); } \\
0.58 \text { (chm); } 0.56 \text { (trn); } 0.66 \text { (ele), } 0.67 \\
\text { (mch); } 0.4 \text { (other sectors) }\end{array}$ & $\begin{array}{l}\text { van der (2007) and Mohler and } \\
\text { Mueller (2012) }\end{array}$ \\
\hline$\sigma_{E}$ & $\begin{array}{l}\text { Electricity and fossil } \\
\text { energy }\left(Y_{\text {fos }}\right)\end{array}$ & 1.8 & $\begin{array}{l}\text { Acemoglu et al. (2012), Bretschger } \\
\text { et al. (2011) }\end{array}$ \\
\hline$\sigma_{\text {ele }}$ & $\begin{array}{l}\text { Electricity generation and } \\
\text { distribution }\end{array}$ & 0 & Bretschger and Zhang (2017b) \\
\hline$\sigma_{\text {egen }}$ & $\begin{array}{l}\text { Electricity generation } \\
\text { groups }\end{array}$ & 10 & Sue Wing et al. (2011) \\
\hline$\sigma_{\text {cons }}$ & $\begin{array}{l}\text { Constant electricity } \\
\text { generation }\end{array}$ & 1.5 & Bretschger and Zhang (2017b) \\
\hline$\sigma_{\text {int }}$ & $\begin{array}{l}\text { Intermittent electricity } \\
\text { generation }\end{array}$ & 2 & Bosetti et al. (2009) \\
\hline$\tau$ & $\begin{array}{l}\text { Non-physical capital }\left(I_{K, i}\right) \text {. } \\
\text { and physical capital }\left(I_{P, i}\right)\end{array}$ & 0.3 & Bretschger et al. (2011) \\
\hline$\omega$ & $\begin{array}{l}\text { Labor in research }\left(L_{R i}\right) \text { and } \\
\text { investments in } R \& D\left(R_{i}\right)\end{array}$ & 0.3 & Bretschger et al. (2011) \\
\hline $1 / \theta$ & $\begin{array}{l}\text { Intertemporal elasticity of } \\
\text { substitution in utility }\end{array}$ & 0.6 & Hasanov (2007) \\
\hline$\sigma_{C}$ & $\begin{array}{l}\text { Energy and non-energy in } \\
\text { consumption }\end{array}$ & 0.5 & ECOPLAN (2007) \\
\hline$\sigma_{c e}$ & $\begin{array}{l}\text { Electricity and fossil } \\
\text { energy in consumption }\end{array}$ & 1.5 & Bretschger and Zhang (2017b) \\
\hline$\eta$ & Trade Armington & $\begin{array}{l}3.2 \text { (agr); } 4.6 \text { (mch); } 3.8 \text { (ele, oin); } 2.9 \\
\text { (other sectors) }\end{array}$ & Donnelly et al. (2004) \\
\hline$\chi$ & Elasticity of transformation & 1 & Bretschger et al. (2011) \\
\hline
\end{tabular}




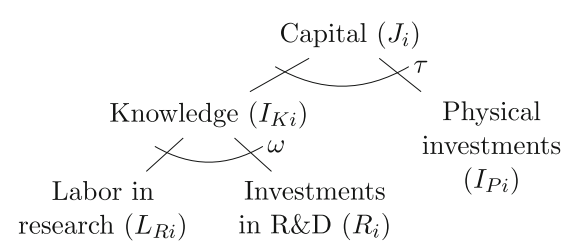

Fig. 2 Capital production

non-physical investments, $I_{K, i}$, are determined by labor in research, $L_{R i}$, non-labor inputs in research $\left(R_{i}\right)$, and the number of intermediate goods, $J_{i}$, following

$$
I_{K i}=\left[\beta_{i}\left(\frac{J_{i}}{z_{i}} L_{R i}\right)^{\frac{\omega-1}{\omega}}+\left(1-\beta_{i}\right) R_{i}^{\frac{\omega-1}{\omega}}\right]^{\frac{\omega}{\omega-1}},
$$

where $\beta$ is the value share, $\omega$ is the elasticity of substitution between $L_{R i}$ and $R_{i}, \frac{J}{z}$ represents a positive spillover from capital variety to labor productivity, and $1 / z$ is the spillover intensity. We assumed a constant research labor, $L_{R i}$, that can be reallocated between sectors.

The model decides the levels of research investments, therefore deriving endogenously all factor productivities. Changes in R\&D increase the number of varieties (following (4)) but they do not change the energy efficiency of a given sector. Specifically, if we assume symmetric intermediate goods in each sector, i.e., $x_{i, j}=x_{i}$, we can derive from (2) the productivity of varieties (capital goods) in the production of the intermediate composite,

$$
\frac{Q_{i}}{J_{i}}=J_{i}^{1 / \kappa-1} x_{i},
$$

which implies that the capital productivity increases with the number of varieties. If all the other resources remain the same, new investments contribute to the productivity improvement along the balanced growth path. When a policy shock changes the price of one factor, for example, the price of the energy input, the relative price change between capital and energy will result in an induced technical change in the firms that allows them to use the relative abundant factor and reduce the use of the scarce factor.

\subsubsection{Energy sector}

In Switzerland, electricity is mainly produced by nuclear power plants and hydropower ${ }^{3}$. Fossil fuels are used mainly in the production of heat in the industry and residential sectors and for mobility. Therefore, we assume that the energy aggregate $Y_{E}$ is produced with two inputs: electricity (non-fossil energy, ele) and fossil energy $\left(Y_{\text {fos }}\right)$

\footnotetext{
${ }^{3}$ In $2017,31.7 \%$ of the Swiss electricity was produced with nuclear power plants, $59.6 \%$ with hydropower, $4 \%$ from renewable fuels, and $4.7 \%$ from waste (Swiss Federal Office of Energy, 2017)
}

assuming a CES function (Fig. 3 shows the nested production function in the energy sector).

Fossil energy is produced using oil and natural gas, which are assumed to trade off in a Cobb-Douglas fashion. The electricity sector is modeled with a CES function that combines electricity generation (egen) and distribution $\left(Y_{\text {ele }}\right)$, which we assume to be perfect complements. Electricity distribution represents the rest of inputs used by the electric utilities and is therefore modeled as a regular sector (Eq. 1).

Generation technologies are divided in three categories: intermittent technologies including wind (win) and solar (sun) power, nuclear power (nuc), and constant electricity supply technologies including hydro power (hyd), conventional thermal plants (ctp), electricity from waste (wel), and biomass (bio) (Bretschger and Zhang, 2017b). After the accident in Fukushima, Switzerland decided to phaseout nuclear power. The phase-out will be done such that no new reactors will be built and the existing ones will operate for as long as they are safe. We model this decision as a gradual phase-out of nuclear reactors from 2020 to 2035, year in which we assume they are completely shut down. Given the nuclear phase-out policy, nuclear is represented as a different technology group whose output is exogenously determined. This classification of the technologies allows us to capture different marginal costs, represents multiple types of generation technologies that are simultaneously dispatched by assuring positive activity levels, and takes into account the intermittency of renewable energy. The trade-offs between and within groups are modeled with CES production functions. Electricity is generated using labor, non-cumulative capital, cumulative capital, and fuels (e.g., nuclear fuel).

\subsubsection{Consumption}

A representative consumer allocates income between consumption and investments to maximize its intertemporal utility under perfect foresight. The household utility $U$ depends on consumption, so that

$$
U=\left[\sum_{t=0}^{\infty}\left(\frac{1}{1+\rho}\right)^{t} C_{t}^{1-\theta}\right]^{\frac{1}{1-\theta}},
$$

where $\rho$ is the utility discount rate and $\theta$ is the inverse of the intertemporal elasticity of substitution. ${ }^{4}$ The infinite time horizon is approximated using the methodology proposed by Lau et al. (2002).

\footnotetext{
${ }^{4}$ Note that the model does not include leisure, which implies a fixed labor supply that does not respond to changes in wages. This is a caveat of the model. However, two characteristics partially compensate this caveat: (1) there are two types of labor in the model, working labor $\left(L_{i, j}\right)$ and research labor , and (2) the overall productivity of the working labor is assumed to increase at the growth rate of GDP to construct the balanced growth path in the benchmark. The overall productivity increase can be interpreted in two ways: a growth in total population and/or improvement in the underlying productivity per worker. Therefore, the fixed labor supply assumption is mitigated to a certain extent.
} 


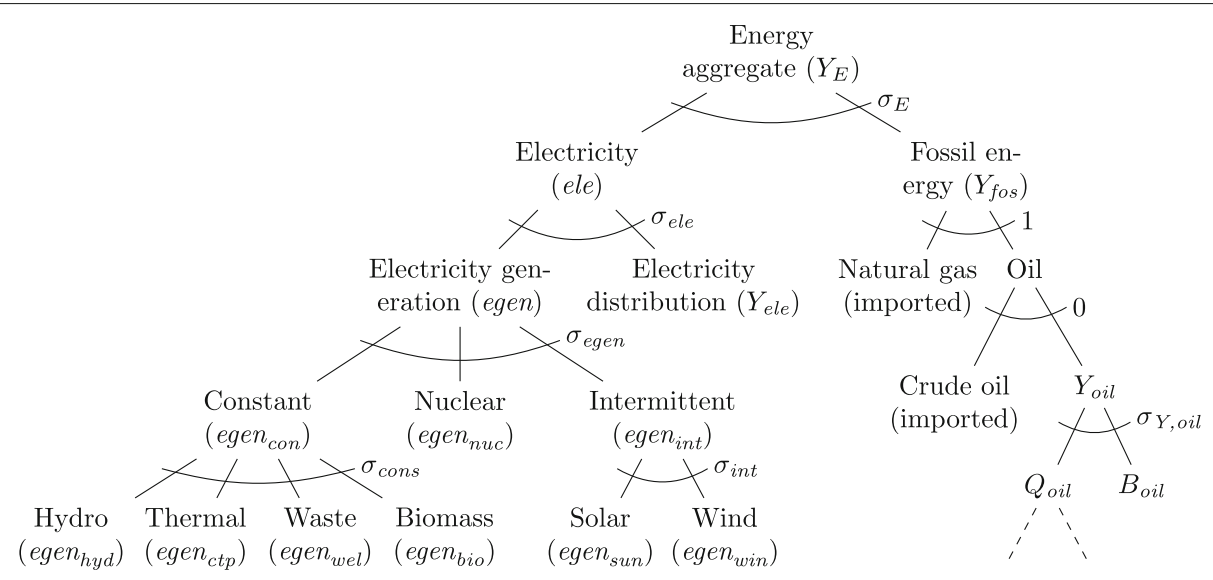

Fig. 3 Nested production function of the Swiss energy sector

In every period, the total consumption $C$ (we omit the temporal subindex) includes the consumption of energy $\left(C_{e n e}\right)$ and the composite of non-energy goods with an elasticity of substitution $\sigma_{C}$; thus,

$$
C=\left[v\left(C_{e n e}\right)^{\frac{\sigma_{C}-1}{\sigma_{C}}}+(1-v)\left(\prod_{n \in N} C_{n}^{\zeta}\right)^{\frac{\sigma_{C}-1}{\sigma_{C}}}\right]^{\frac{\sigma_{C}}{\sigma_{C}-1}}
$$

where $\zeta$ is the consumption share of $\operatorname{good} n\left(\sum_{n \in N} \zeta=\right.$ $1)$ and $N$ is the set of all non-energy goods. Energy consumption consists of electricity consumption $C_{\text {ele }}$ and the consumption of fossil fuels $C_{f o s}$ in a CES fashion,

$$
C_{\text {ene }}=\left[\sigma C_{\text {ele }}^{\frac{\sigma_{c e-1}}{\sigma_{c e}}}+(1-\sigma) C_{f o s}^{\frac{\sigma_{c e-1}}{\sigma_{c e}}}\right]^{\frac{\sigma_{c e}}{\sigma_{c e-1}}} .
$$

\subsubsection{Trade}

The economy is open to international trade of regular and energy goods model through Armington demand functions. Markets for final goods are assumed to be perfectly competitive.

The sectoral output $Y_{i}$ can be used for domestic use $\left(D_{i}\right)$ and exports $\left(P_{i}\right)$ :

$$
Y_{i}=\left[\alpha_{d i} D_{i}^{1+\chi_{i}}+\left(1-\alpha_{d i}\right) P_{i}^{1+\chi_{i}}\right]^{\frac{1}{1+\chi_{i}}}
$$

assuming a Constant Elasticity of Transformation technology with $\chi_{i}$ elasticity of transformation.

In each sector, domestic output $D_{i}$ and imported goods $M_{i}$ are combined to yield an Armington good $A_{i}$ that is available for consumption; thus,

$$
A_{i}=\left[v_{i} M_{i}^{\frac{\eta_{i}-1}{\eta_{i}}}+\left(1-v_{i}\right) D_{i}^{\frac{\eta_{i}-1}{\eta_{i}}}\right]^{\frac{\eta_{i}}{\eta_{i}-1}}
$$

where $\eta_{i}$ reflects the market power of the domestic economy. Foreign prices are exogenous to the model. Trade is balanced in every period.

\subsubsection{Data and calibration}

Table 1 presents the values and the references for the different parameters used in the model.

The benchmark is calibrated to a balanced growth path, where all variables grow at a constant rate, and this includes all sectoral outputs and the components of the aggregate consumption and production. This requires the same capital share $(1-\kappa)$ in all sectors; different sectoral capital shares would imply different sectoral growth rates. In the data, however, capital shares are not the same across sectors. Therefore, we split the initial capital into $J$ (which can be accumulated following (4)) and a residual non-cumulative capital $V$ that is used in the production of intermediates (see (3)).

We calibrate the model to the Swiss Social Accounting Matrix (SAM) of the year 2008 in the version by Peter et al. (2013), which provides a detailed disaggregation of the energy and transportation industries and additional information regarding energy production and consumption in physical units that are consistently linked with economic data in value terms. In particular, we use the SAM data to calibrate the cost functions of sectoral production, sectoral investment, household consumption preference, and international trade. To reduce the computational complexity while keeping the key structure of the Swiss economy, around a hundred sectors are aggregated into ten non-energy sectors, three fossil energy sectors, and one electricity sector with seven generation technologies ${ }^{1}$. We then construct the trajectory of the Swiss economy over time along the balanced growth path starting from the 
calibrated base year (Peter et al., 2013) and the harmonizing assumptions in the SEMP study (see Table 2). These assumptions imply a benchmark scenario with a GDP increase of $66 \%$ by 2050 relative to the level of 2010 and an increase in labor from 3.85 million full-time equivalents in 2010 to 4.63 million in 2050 .

\subsection{Analyzed scenarios}

The Federal Council defined a long-term objective of reducing GHG emissions in 2050 by $70-80 \%$ relative to 1990 levels (equivalent to $1-2 \mathrm{tCO}_{2 e}$ per capita). In the SEMP modeling comparison (Landis et al., 2019), we analyze two alternative $\mathrm{CO}_{2}$-only targets for 2050 that are consistent with the goals of reducing GHG emissions to $1.5 \mathrm{tCO}_{2 e}$ and $1.0 \mathrm{tCO}_{2 e}$ per capita. Using the SEMP harmonized assumption of population (see Table 2), these two targets correspond to a decrease in $\mathrm{CO}_{2}$ emissions of $72 \%$ and $80 \%$ relative to 1990 levels $\left(12.9 \mathrm{MtCO}_{2}\right.$ and $8 \mathrm{MtCO}_{2}$ ), respectively ${ }^{5}$. We assume a linear decrease of $\mathrm{CO}_{2}$ emissions between 2020 and 2050 as shown in Table 2 .

The Swiss Federal Council intends to move away from subsidies to renewable energies and energy efficiency measures to steering-based climate policies, where carbon prices are used to meet the climate targets (Swiss Federal Council, 2015a, b). We therefore consider three alternative carbon tax schemes:

1. Economy-wide $\mathrm{CO}_{2}$ tax: $\mathrm{A}$ uniform carbon tax is applied across the whole economy.

2. ETS and uniform $\mathrm{CO}_{2}$ tax: Carbon taxes are separated between ETS and non-ETS sectors. ETS sectors have a cap on emissions with a yearly reduction factor of $1.74 \%$ (see Table 2), which is the rate used in the EU ETS until 2020. Emissions from non-ETS sectors have a uniform carbon tax.

3. ETS and differentiated $\mathrm{CO}_{2}$ tax: ETS sectors are modeled as in the previous schemes. Non-ETS sectors are differentiated between transport and heating fuels. The $\mathrm{CO}_{2}$ taxes on transport fuels are one fourth of the taxes on heating fuels.

The results of the policy scenarios are compared to a business-as-usual (BAU) scenario where current climate policies are assumed to continue, but are not intensified. We assume a potential annual economic growth rate in the $B A U$ of $1.28 \%$ following the projections of the State Secretariat for Economic Affairs (SECO), a levy on heating fuels from the $\mathrm{CO}_{2}$ ordinance (Swiss Federal Council, 2013) that reaches a level of $120 \mathrm{CHF} / \mathrm{tCO}_{2}$ in 2020 , and the cap on ETS emissions used in the policy scenarios. Table 2 summarizes the assumptions in the BAU scenario.

${ }^{5}$ We assume that the reduction in $\mathrm{CO}_{2}$ emissions is proportional to the reduction in GHG emissions and that the target is met domestically.

\section{Scenario effects on the macro-economy}

The policies modeled in the BAU scenario lead (in our simulation results) to a reduction in $\mathrm{CO}_{2}$ emissions by 2050 of $54 \%$ compared to 2010 levels. Using the population assumptions in Table 2, this reduction corresponds to a level of GHG emissions per capita in 2050 of $2.8 \mathrm{tCO}_{2}$ p.c. ${ }^{6}$ In this section, we present the results of our policy simulations as changes in macro-economic indicators relative to this BAU scenario.

\subsection{The effect of increasing the stringency of the target}

The first research question we answer in the paper is what are the effects of increasing the climate target from a BAU scenario, in which emissions per capita in 2050 are 2.8 $\mathrm{tCO}_{2}$ p.c., to two climate scenarios with targets of 1.5 and $1.0 \mathrm{tCO}_{2}$ p.c.

The first row in Table 3 presents the changes in utility (life-time cumulative discounted consumption as shown in Eq. 7) in the different scenarios compared to the BAU case. ${ }^{7}$ In our simulations, using an economy-wide tax, the changes to the economy needed to reduce per capita emissions in 2050 by half (from 2.8 to $1.5 \mathrm{tCO}_{2}$ p.c.) imply utility losses of $1.69 \%$. The extra efforts needed to further reduce emissions to one third of the BAU emissionsfrom 2.8 to $1.0 \mathrm{tCO}_{2}$ p.c.-represent one additional percentage point in utility losses $(2.64 \%)$. We find that the difference in utility between targets (around 1 p.p.) is roughly the same in all policy designs. The changes in utility (using the economy-wide uniform tax) correspond to a reduction in the growth rate of consumption of 0.2 and 0.3 p.p. (see second row in Table 3).

Besides consumption, other important macroeconomic indicators of the consequences of the climate policies are investments and economic output. In our simulations, the growth rate of total investments is higher for the scenarios with climate policies than in the BAU (third row in Table 3). This can be explained by the inelastic labor supply assumed in the CITE model (see Eq. 7). As shown by Karydas and Zhang (2017), if leisure is disregarded (inelastic labor supply), an increase in energy price due to the carbon taxation can promote economic growth. This is due to the mobile labor between manufacturing and research and the limited substitution between labor and energy inputs in manufacturing. Carbon taxes reduce the demand for energy goods. Given the limited substitutability between inputs this lower energy demand implies a reduction in the demand for labor in manufacturing and therefore an increase in labor in research activities. Higher innovation can lead

\footnotetext{
${ }^{6}$ Note that we assume again a reduction in GHG emissions proportional to the reduction in $\mathrm{CO}_{2}$-only emissions as we did to calculate the $\mathrm{CO}_{2}$ targets. ${ }^{7} \mathrm{We}$ only take into account the non-environmental economic impacts of the climate policies. Positive externalities from improved environmental quality as a result of the climate policies are excluded from the study.
} 
Table 2 Harmonizing assumptions and $\mathrm{CO}_{2}$ targets

\begin{tabular}{|c|c|c|c|c|c|}
\hline & 2010 & 2020 & 2035 & 2050 & Reference \\
\hline \multicolumn{6}{|l|}{ Harmonizing assumptions } \\
\hline Population (million) & 7.8 & 8.7 & 9.8 & 10.3 & BFS Scenario A-00-2015 (BFS, 2015) \\
\hline Working population (million full time eq.) & 3.85 & 4.31 & 4.58 & 4.63 & BFS Scenario A-00-2015 (BFS, 2015) \\
\hline Cap on emissions from ETS sectors (relative to 2013) ${ }^{a}$ & & 0.88 & 0.68 & 0.52 & EU ETS yearly reduction \\
\hline \multicolumn{6}{|l|}{$\mathrm{CO}_{2}$ targets } \\
\hline $1.5 \mathrm{tCO}_{2 e}$ target & 1 & 0.849 & 0.571 & 0.284 & SEMP (Landis et al., 2019) \\
\hline $1.0 \mathrm{tCO}_{2 e}$ target & 1 & 0.824 & 0.510 & 0.189 & SEMP (Landis et al., 2019) \\
\hline \multicolumn{6}{|l|}{ BAU scenario } \\
\hline Potential GDP (rel. to 2010) & 1 & 1.18 & 1.43 & 1.66 & SECO $2015^{b}$ \\
\hline Total energy use (rel. to 2010) & 1 & 0.94 & 0.84 & 0.78 & BAU scenario, Prognos (2012) \\
\hline $\mathrm{CO}_{2}$ tax heating fuels $\left(\mathrm{CHF} / \mathrm{tCO}_{2}\right)$ & 36 & 120 & 120 & 120 & $\mathrm{CO}_{2}$ Levy (Swiss Federal Council, 2013) \\
\hline $\mathrm{CO}_{2}$ tax transport fuels $\left(\mathrm{CHF} / \mathrm{tCO}_{2}\right)$ & 0 & 0 & 0 & 0 & $\mathrm{CO}_{2}$ Levy (Swiss Federal Council, 2013) \\
\hline
\end{tabular}

${ }^{a}$ The cap is computed using a yearly reduction factor of $1.74 \%$ used in the EU ETS until 2020

${ }^{b}$ Data provided by the Swiss State Secretariat for Economics Affairs (SECO)

Table 3 Macro-economic effect of simulated scenarios

\begin{tabular}{|c|c|c|c|}
\hline & \multicolumn{3}{|l|}{ Target } \\
\hline & $1.5 \mathrm{tCO}_{2}$ p.c. & & $1.0 \mathrm{tCO}_{2}$ p.c. \\
\hline \multicolumn{4}{|l|}{ Changes in utility [\%] } \\
\hline Economy-wide $\mathrm{CO}_{2}$ tax & -1.69 & & -2.64 \\
\hline ETS and uniform $\mathrm{CO}_{2}$ tax & -1.62 & & -2.63 \\
\hline $\begin{array}{l}\text { ETS + differentiated } \mathrm{CO}_{2} \\
\operatorname{tax}\end{array}$ & -2.35 & & -3.41 \\
\hline \multicolumn{4}{|l|}{$\begin{array}{l}\text { Aggregate growth of con- } \\
\text { sumption [\%] }{ }^{a}\end{array}$} \\
\hline BAU & & 1.18 & \\
\hline Economy-wide $\mathrm{CO}_{2}$ tax & 0.97 & & 0.89 \\
\hline ETS and uniform $\mathrm{CO}_{2}$ tax & 0.97 & & 0.89 \\
\hline $\begin{array}{l}\text { ETS + differentiated } \mathrm{CO}_{2} \\
\operatorname{tax}\end{array}$ & 0.93 & & 0.86 \\
\hline \multicolumn{4}{|l|}{$\begin{array}{l}\text { Aggregate growth of } \\
\text { investments [\%] }\end{array}$} \\
\hline BAU & & 1.22 & \\
\hline Economy-wide $\mathrm{CO}_{2}$ tax & 1.68 & & 1.77 \\
\hline ETS and uniform $\mathrm{CO}_{2}$ tax & 1.65 & & 1.73 \\
\hline $\begin{array}{l}\text { ETS + differentiated } \mathrm{CO}_{2} \\
\operatorname{tax}\end{array}$ & 1.63 & & 1.70 \\
\hline \multicolumn{4}{|l|}{$\begin{array}{l}\text { Aggregate growth of out- } \\
\text { put [\%] }\end{array}$} \\
\hline BAU & & 1.23 & \\
\hline Economy-wide $\mathrm{CO}_{2}$ tax & 1.209 & & 1.229 \\
\hline ETS and uniform $\mathrm{CO}_{2}$ tax & 1.206 & & 1.231 \\
\hline$\underset{\operatorname{tax}}{E T S}+$ differentiated $\mathrm{CO}_{2}$ & 1.210 & & 1.233 \\
\hline
\end{tabular}

${ }^{a}$ Growth rates in this table are calculated as the annual average growth rate of aggregate between 2010 and 2050, in percentage to higher investment levels in the scenarios with carbon targets. Our results show higher investment levels with the increase in stringency of the target (growth rate of $1.77 \%$ compared to $1.68 \%$ ). Higher investments partially compensate for the reduction in output due to the carbon policies, as shown by the growth rates of aggregate output that remain relatively unaffected (see last row in Table 3).

At the sectoral level, the introduction of the tax leads to important structural effects. The first column in Table 4 shows the changes in the 2050 output compared to the BAU. We present the results for the $1.5 \mathrm{tCO}_{2}$ target because results for the $1.0 \mathrm{tCO}_{2}$ target are similar and qualitatively the same analysis holds. Changes in sectoral output range from an increase of $18 \%$ in the chemistry industry $(\mathrm{CHM})$ to a $25 \%$ reduction in other industries (OIN, which includes heavy industries such as cement and steel production) and a significant decrease in the sectoral output of the energy sectors. Four sectors have a higher output level in 2050 when applying the carbon targets: chemistry, insurance, construction, and machinery.

The interplay of different mechanisms drives these structural changes. First, energy intensive sectors are more affected by the climate policy because the carbon tax implies higher energy prices. Transport, agriculture, and other industries have the highest share of energy used in the production of the output (around 10\%). These are precisely the sectors with the highest reductions in total output. On the contrary, machinery, chemical industries, and the service sectors (including banking and other services) have low energy intensities and are less affected by the climate policy. Following this driver only, one would expect gains in economic output from those three sectors. However, the level of substitution from energy in 
Table 4 Changes in 2050 output, investment, high-skilled labor and terminal capital by sector in $1.5 \mathrm{tCO}_{2}$ p.c. scenario (in percentage relative to $\mathrm{BAU}$ )

\begin{tabular}{lllll}
\hline Sector & Output $\left(Y_{i}\right)$ & Investment & $\begin{array}{l}\text { Labor in } \\
\text { research } \\
\left(L_{R i}\right)\end{array}$ & Terminal capital \\
\hline CHM & 18.27 & 21.49 & 23.48 & 16.83 \\
INS & 14.70 & 32.85 & 174.50 & 31.95 \\
CON & 12.58 & 26.82 & 29.88 & 19.31 \\
MCH & 11.41 & 3.82 & -48.92 & 12.81 \\
BNK & 0.47 & 7.18 & -0.21 & 4.56 \\
OSE & -2.01 & 6.84 & -5.24 & 4.54 \\
HEA & -5.65 & -1.11 & -16.42 & -0.68 \\
TRN & -21.99 & 2.82 & -14.93 & 2.62 \\
AGR & -22.27 & -5.80 & -30.90 & -4.56 \\
OIN & -25.10 & -11.06 & -40.50 & -6.87 \\
Energy sectors & & & \\
ELES & -14.80 & 33.00 & 33.23 & 31.09 \\
OIL & -48.04 & -45.83 & -5.35 & -46.91 \\
HET & -60.37 & -100 & -100 & -100 \\
GAS & -74.71 & -100 & -100 & -100 \\
\hline
\end{tabular}

the production of the intermediate varieties impacts the results. We assume that the OSE sector has lower substitution possibilities (see Table 1) resulting in a slightly lower output ( $-2 \%$ compared to BAU). The third mechanism driving the results is the increase in investment due to substitution of energy with capital and the shift of labor from manufacturing to research. This is illustrated in the second and third columns in Table 4 that show the changes in investments and labor in research for the year 2050. This driver fosters growth in the chemistry, insurance, and construction sectors. An interesting case is the transport sector, where output decreases (relative to BAU) despite the increase in investments. The transport sector in the BAU scenario has a significant growth that relies on fossil fuels. The climate policies imply a reduction in the use of fossil fuels, but at the same time, an increase in both physical and R\&D investments is needed for the energy transition (development of infrastructure and new technologies). Finally, the reduction in the use of fossil fuels and nuclear causes the decrease in output of the energy sectors. However, investments and R\&D increase for electricity while they decrease for the fossil fuels due to the climate policy.

The changes in capital stocks from the BAU scenario (see last column in Table 4) are roughly similar to the changes in sectoral output. This means that capital shifts to the least energy intensive sectors, which become more attractive for investors since they are less affected by the higher energy prices resulting from the carbon taxes. In the CITE model, the growth mechanism is the increase in varieties, that is the increase in capital stock. Sectors with higher capital stock have the higher economic growth. Despite the relative changes in capital accumulation in the different sectors, the growth rate of all sectors and, therefore, the growth rate of the economy remain positive when implementing the carbon policies.

\subsection{Alternative carbon tax schemes}

Table 3 presents the effects on utility, consumption, investment, and economic output of the economy-wide tax and the alternatives of differentiating ETS sectors ${ }^{8}$ and transport and heating fuels. Comparing the changes in utility, we find that differentiating ETS and non-ETS sectors does not have an important effect. However, when the non-ETS sectors are further differentiated between transport and heating fuels, utility is significantly reduced. In our simulations, differentiating the carbon taxes implies lower abatement and lower carbon prices for the differentiated sector (see Fig. 4). Therefore, the differences in utility losses arise from the different additional abatement undertaken by the non-differentiated sectors. Emissions from ETS sectors in the uniform economy-wide carbon tax scheme are reduced by $75 \%$ and $83 \%$ in 2050 , while we assumed, in the differentiated tax schemes, an emissions reduction target of $52 \%$ (see Table 2). However, ETS emissions account in our calibration for only $10 \%$ of total emissions, so the additional abatement that takes place in the other sectors is relatively low and the whole economy remains practically unaffected. On the contrary, when further differentiating the non-ETS sectors, the cap on emissions from ETS sectors remains but the carbon price on transport fuels-that accounts for $17 \%$ of today's emissions-is reduced by $1 / 3$ (Fig. 4c, f). Therefore, the rest of the economy (non-ETS sectors excluding transport) undertakes a significantly higher abatement, resulting in larger utility losses.

However, the sectoral-differentiating scenarios do not result in significant changes in terms of total investments, which sustain economic output (see last two rows in Table 3). To better understand these findings, Table 5 presents the growth rate of the sectoral outputs for the $1.5 \mathrm{tCO}_{2}$ p.c. scenario (the same analysis holds for the $1.0 \mathrm{tCO}_{2}$ scenario). Although the whole economy continues to have an annual growth rate of $1.2 \%$, there are two important effects on the sectoral decomposition: First, since the cap on emissions from ETS sectors is lower than the emission reductions obtained when applying an economy-wide carbon tax, the resulting ETS carbon price is lower (see Fig. 4b, e). The lower carbon price on ETS

${ }^{8}$ We assume chemistry (CHM) and other industries (OIN) to be the ETS sectors in the model. 


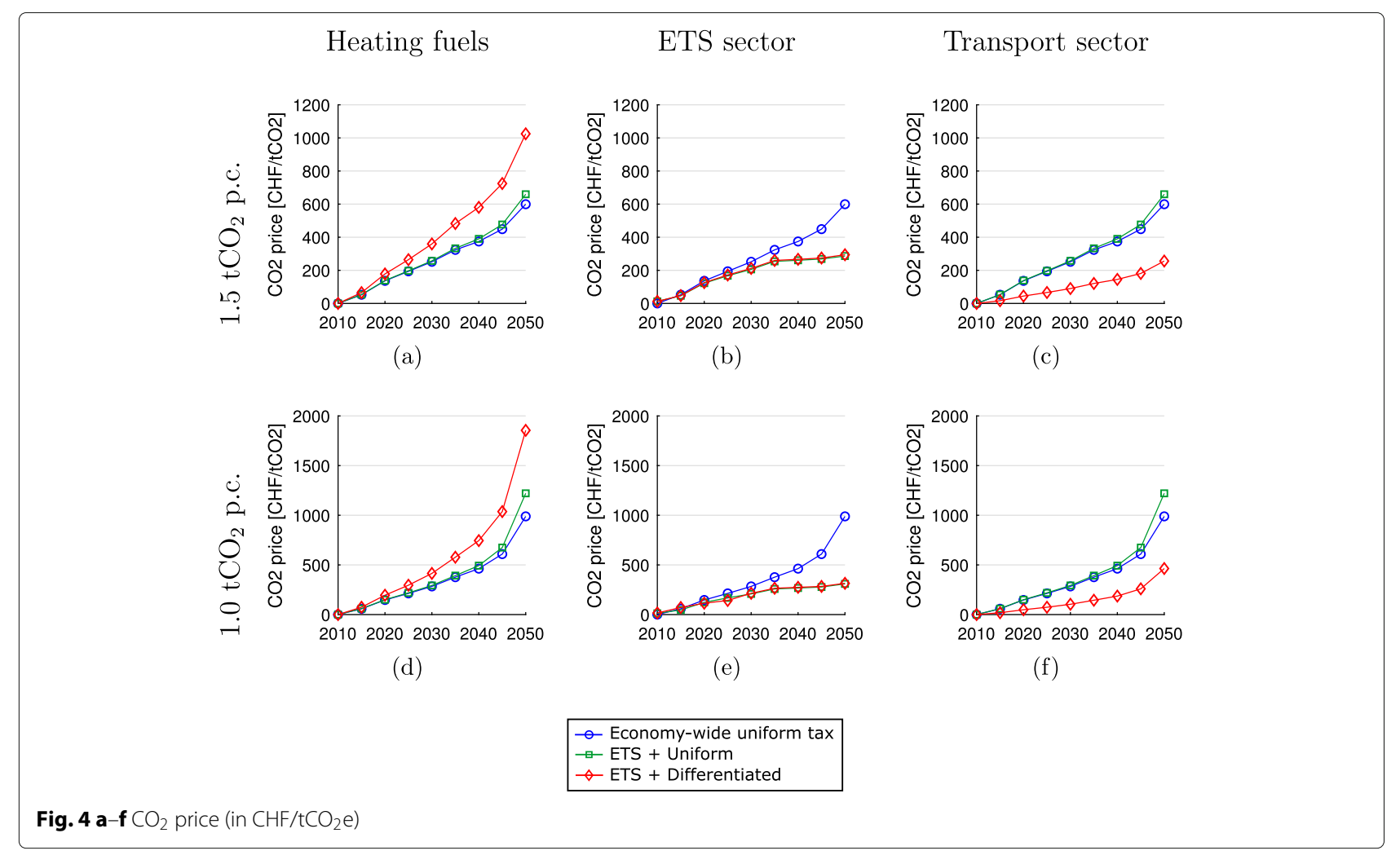

Table 5 2010-2050 growth rate of output (in percentage)

\begin{tabular}{cccc}
\hline Sector & Economy-wide & ETS and uniform & ETS + differentiated \\
\hline \multicolumn{2}{c}{ ETS sectors } & & \\
CHM & 1.48 & 1.33 & 1.29 \\
OIN & 0.05 & 0.22 & 0.21 \\
Transport sector & & \\
TRN $\quad 0.31$ & 0.29 & 0.45 \\
Other non-ETS sectors & & \\
AGR & 0.27 & 0.38 & 0.36 \\
MCH & 2.05 & 2.02 & 2.07 \\
CON & 1.54 & 1.51 & 1.50 \\
BNK & 1.39 & 1.39 & 1.39 \\
INS & 2.15 & 2.16 & 2.15 \\
HEA & 1.09 & 1.10 & 1.07 \\
OSE & 1.23 & 1.23 & 1.22 \\
Energy sectors & & -1.25 \\
ELES & -1.25 & -1.26 & -3.34 \\
OIL & -3.50 & -3.51 & -6.65 \\
GAS & -5.61 & -5.34 & -3.32 \\
HET & -3.36 & -2.82 & \\
\hline
\end{tabular}

sectors allows a higher growth in the OIN sector (from 0.05 to $0.22 \%$ ), which was significantly penalized by the uniform carbon tax due to its high energy intensity. This implies a slight reduction of the growth rate of the CHM sector, but overall, the ETS sectors continue to grow at an annual rate of $0.7 \%$. All non-ETS sectors remain relatively unaffected, and the higher emissions from the ETS sectors are compensated by a small reduction in the economic output of transport.

Second, in the scenario where transport fuels have a lower carbon tax than heating fuels, the transport sector has a higher growth rate (from 0.31 to $0.45 \%$ ) implying higher abatement in other sectors and a reduction in overall consumption. Since transport fuels have a lower carbon tax, the incentive for carbon abatement in the transport sector is reduced. To achieve the same carbon mitigation target, other sectors which are not entitled to the tax reduction have to make greater efforts compared to the uniform tax case. Therefore, those sectors result in a lower production and higher prices. In the end, the consumers lower the consumption of goods produced from these sectors. Our model does not include preexisting tax distortions in the transport sector. These distortions could reduce the increase in consumption in the transport sector and therefore reduce the additional abatement needed in the rest of the economy. 


\section{Discussion and policy implications}

This paper studies the growth effects of two long-term climate change mitigation goals and alternative steeringbased policies on the Swiss economy using a computable general equilibrium model with endogenous growth - the CITE model. Our results show that if R\&D is the driven mechanism for economic growth in the economy, climate policies might lead to an increase in investments and long-term capital through the shift of labor from manufacturing to research.

We analyze two alternative long-term targets for Swiss emissions: 2050 per capita GHG emissions of $1.5 \mathrm{tCO}_{2}$ and $1.0 \mathrm{tCO}_{2}$. We compared these two targets to a BAU scenario with per capita GHG emissions by 2050 of 2.8 $\mathrm{tCO}_{2}$ p.c. We find that realizing the climate targets has some negative impacts on private consumption (a reduction in annual growth rate of -0.21 and -0.28 p.p) but positive effects on investments (an increase in the annual growth rate of +0.46 and +0.55 p.p) and relatively unchanged economic growth driven by sectoral shifts. The structure of the economy adjusts following the interplay of three factors: relative energy intensity of the sectors, substitutability from energy in the production of the intermediate varieties, and the relative attractiveness of research. The third effect is achieved with the endogenous growth mechanism and implies larger investments due to the shift of labor from manufacturing to research. Since the economic structure adjusts in favor of sectors with relatively high capital intensity and low energy intensity, besides carbon taxes, complementary policies to achieve the climate goals could include changes in capital taxation to give incentives to innovation.

The mitigation targets analyzed in this paper correspond to a total reduction in $\mathrm{CO}_{2}$ emissions of $72 \%$ and $80 \%$ relative to 1990 levels. Our results are consistent with previous studies using the CITE model. For instance, Bretschger et al. (2011) find utility losses for a scenario with an $80 \%$ emissions reduction of $2.6 \%$ compared to the benchmark scenario, and Karydas and Zhang (2017) find changes in utility for a $60 \%$ emissions reduction of $3.79 \%$ from BAU. However, compared to the models in the SEMP study, the changes in utility from the CITE model are higher. The results from the other models are in the ranges of $0.16-0.36 \%$ and $0.24-0.48 \%$ for the 1.5 $\mathrm{tCO}_{2}$ per capita and the $1.0 \mathrm{tCO}_{2}$ p.c. targets, respectively (Landis et al., 2019). The other models in the SEMP study include two recursive-dynamic models and one static CGE. The main reason for these differences is that the CITE model is the only one with a life-time cumulative discounted consumption (the discount rate used in the model is $4 \%$ ). If the problem of the representative household is to maximize the life-time consumption and she foresees that the consumption will be significantly reduced by the policy shock in the future, the optimal strategy is to consume less at the beginning in order to invest for future consumption. A recent study on the EU energy policy that analyzes the EU climate target of reducing GHG emissions by $80 \%$ in 2050 compared to 1990 levels finds slightly lower changes in utility of -0.7 p.p. but higher losses in total economic output of -0.25 p.p (Fragkos et al., 2017). An important economy for the global climate change mitigation goals is China. Bretschger and Zhang (2017a) analyze a scenario for China with a target of reducing carbon intensity by $65 \%$ in 2030. They found a reduction in annual consumption growth of 0.4 p.p. compared to the benchmark. The consumption losses are higher than in our case given China's currently dependency on fossil fuels.

Concerning the steering-based alternatives, we find that the economy-wide carbon tax is the most effective option if we consider the effects on utility. Differentiating ETS and non-ETS sectors has relatively low impact while applying a scheme where the tax on transport fuels is $25 \%$ of the tax on heating fuels has a negative effect on utility. This is driven by the relative contribution of the sectoral emissions to total emissions and the relative changes in the carbon prices of the differentiated sectors. Therefore, an important part of the policy design is determining the appropriate cap for the ETS sectors or the appropriate rate of tax differentiation. We showed that a relatively low cap on ETS or transport emissions (equivalent to the low tax) implies an increase in the abatement effort of the rest of sectors, which could lead to an overall decrease in utility. However, these results might change if all pre-existing taxes and (negative) externalities in the transport sector are taken into account. Another important finding from our analysis is that the relative changes in consumption due to an increase in the stringency of the target are independent from the policy setting.

An important assumption in our simulations is the redistribution of carbon revenues. We assume that carbon revenues are rebated to the households through lumpsum transfers. Other studies using the CITE model show that if carbon revenues are used as a subsidy for research activities (Bretschger et al., 2011) or to lower capital taxation (Karydas and Zhang, 2017), the effects on consumption can be reduced. This is an important point in terms of policy design.

In the model, we assume that investors have perfect information concerning current and future policies. Our results show that economic growth is sustained via investments and endogenous innovation. We know that future policy decisions are highly uncertain, which could substantially increase the policy cost. Without complete information on the future policy agenda, firms face difficulties in making optimal investment decisions. Therefore, a regulatory framework that is transparent, 
consistent over time, and early announced could foster economic growth even in the presence of stringent climate targets as in the case of the Swiss climate policy.

There are some external costs missing in the model. For instance, the costs of decommissioning nuclear plants and waste disposal, the costs of building up renewable capacities and back-up technologies, the costs for remote grids for renewable energies, etc. Moreover, avoided damages from climate change mitigation are not included (for example, health costs associated with fossil fuel-related air pollutants). All of these aspects are beyond the scope of the paper. Additional exercises are needed to further introduce those aspects in a macroeconomic model for studying the technology landscape of Swiss climate policies.

\section{Abbreviations \\ BAU: Business as usual; CES: Constant elasticity of substitution; CHF: Swiss Franc; CITE: Computable Induced Technical change and Energy; CGE: Computable general equilibrium; ETS: Emission trading system; GDP: Gross Domestic Product; GHG: Greenhouse gas; NDC: Nationally Determined Contribution; SEMP: Swiss Energy Modelling Platform; R\&D: Research and development; SAM: Social Matrix Accounting; SECO: State Secretariat for Economic Affairs; Sectors: agr: Agriculture; bnk: banking and financial services; chm: Chemical industry; con: Construction ; ele: Electricity; hea: Health; het: Heat; ins: Insurances; mch: Machinery; oin: Other industries; ose: Other services; trn: Transport; Electricity generation technologies: bio: biomass; ctp: Conventional thermal plants; hyd: Hydro power; nuc: Nuclear power; sun: Solar power; wel: Electricity from waste; win: Wind power}

\section{Acknowledgements}

We would like to thank the modeling teams in the SEMP model comparison exercise and the valuable remarks of the editor Frank Krysiak and the two unknown referees.

\section{Authors' contributions}

Both authors contributed to the modeling, analysis of the results, and writing the paper. Both authors read and approved the final manuscript.

\section{Funding}

This research is part of the activities of SCCER CREST, which is financially supported by Innosuisse (Suisse Innovation Agency).

\section{Availability of data and materials}

The CITE model used in this paper is described in Bretschger et al. (2011). The datasets generated and analyzed during the current study are partially available in the SEMP Webpage,

simlab.ethz.ch \1stSemp_results.php.

\section{Competing interests}

The authors declare that they have no competing interests

\section{Author details}

${ }^{1}$ ETH Zurich, Center of Economic Research, 8092 Zurich, Switzerland. ${ }^{2}$ School of Energy and Environment and Department of Public Policy, City University of Hong Kong, Hong Kong, China.

Received: 26 February 2018 Accepted: 15 August 2019

Published online: 13 September 2019

\section{References}

Abrell, J, Rausch, S, Schwarz, G.A (2018). How robust is the uniform emissions pricing rule to social equity concerns? Journal of Environmental Economics and Management, 92, 783-814.

Acemoglu, D, Aghion, P, Bursztyn, L, Hemous, D (2012). The environment and directed technical change. American Economic Review, 102(1), 131-166.
BFS (2015). Szenarien zur Bevoelkerungsentwicklung der Schweiz Neuchâtel: Bundesamt für Statistik (BFS).

Boeters, S (2014). Optimally differentiated carbon prices for unilateral climate policy. Energy Economics, 45, 304-312.

Böhringer, C, Lange, A, Rutherford, T.F (2014). Optimal emission pricing in the presence of international spillovers: Decomposing leakage and terms-of-trade motives. Journal of Public Economics, 110, 101-111.

Böhringer, C, \& Müller, A (2014). Environmental tax reforms in Switzerland a computable general equilibrium impact analysis. Swiss Journal of Economics and Statistics, 150, 1-21.

Bosetti, V., Tavoni, M., De Cian, E., Sgobbi, A. (2009). The 2008 WITCH model: New model features and baseline: FEEM Working Paper, 2009.085, Fondazione Eni Enrico Mattei, Venice, Italy.

Bretschger, L, Ramer, R, Schwark, F (2011). Growth effects of carbon policies: Applying a fully dynamic CGE model with heterogeneous capital. Resource and Energy Economics, 33, 963-980. Special section: Sustainable Resource Use and Economic Dynamics.

Bretschger, L, \& Zhang, L (2017a). Carbon policy in a high-growth economy: The case of China. Resource and Energy Economics, 47, 1-19.

Bretschger, L, \& Zhang, L (2017b). Nuclear phase-out under stringent climate policies: A dynamic macroeconomic analysis. The Energy Journal, 38, 167-194.

Donnelly, W.A., Johnson, K., Tsigas, M.E., Ingersoll, D.L. (2004). Revised armington elasticities of substitution, usitc model and the concordance for constructing consistent set for the gtap model: USITC Office of Economics Research. Note No. 20001-A.

ECOPLAN (2007). Auswirkungen langfristig hoher Ölpreise. Einfluss eines hohen langfristigen Ölpreises aufWirtschaftswachstum, Strukturwandel sowie Energieangebot und -nachfrage. Bern: Ecoplan.

Fragkos, P, Tasios, N, Paroussos, L, Capros, P, Tsani, S (2017). Energy system impacts and policy implications of the european intended nationally determined contribution and low-carbon pathway to 2050. Energy Policy, 100, 216-226.

Hasanov, F. (2007). Housing, household portfolio, and intertemporal elasticity of substitution: evidence from the consumer expenditure survey. Macroeconomics 0510011 , University Library of Munich, Germany.

Hoel, M (1996). Should a carbon tax be differentiated across sectors? Journal of Public Economics, 59, 17-32.

Kannan, R, \& Turton, H (2016). Long term climate change mitigation goals under the nuclear phase out policy: The swiss energy system transition. Energy Economics, 55, 211-222.

Karydas, C, \& Zhang, L (2017). Green tax reform, endogenous innovation and the growth dividend. Journal of Environmental Economics and Management. In press.

Landis, F, Marcucci, A, Rausch, S, Kannan, R, Bretschger, L (2019). Multi-model comparison of swiss decarbonization scenarios. Swiss Journal of Economics and Statistics.

Landis, F, Rausch, S, Kosch, M (2018). Differentiated carbon prices and the economic cost of decarbonization. Environmental and Resource Economics, 70, 483-516.

Lau, M.I, Pahlke, A, Rutherford, T.F (2002). Approximating infinite-horizon models in a complementarity format: A primer in dynamic general equilibrium analysis. Journal of Economic Dynamics and Control, 26, 577-609.

Marcucci, A, \& Turton, H (2012). Swiss energy strategies under global climate change and nuclear policy uncertainty. Swiss Journal of Economics and Statistics, 148, 317-345.

Markusen, J (1975). International externalities and optimal tax structures. Journal of International Economics, 5, 15-29.

Mohler, L., \& Mueller, D. (2012). Substitution elasticities in Swiss manufacturing: Wirtschaftswissenschaftliche Fakultät, Unibas and Institut für Wirtschaftsstudien, Basel, Switzerland. Study commissioned by Swiss Federal Office of Energy.

Okagawa, A, \& Ban, K (2008). Estimation of substitution elasticities for CGE models. Graduate School of Economics and Osaka School of International Public Policy, Discussion Paper, 08-16.

Peter, M., van Nieuwkoop, R., Nathani, C., Sutter, D., Kraner, S. (2013). Energy related disaggregation of the Swiss IOT 2008 and revision of energy-IOT 2001 and 2005. Bern: SFOE, EWG Publication 290843.

Prognos (2012). Die Energieperspektiven fuer die Schweiz bis 2050: Technical Report Bundesamt für Energie. Basel: Prognos AG. 
Romer, P (1990). Endogenous technical change. The Journal of Political Economy, 98, S71-S102.

Sceia, A, Altamirano-Cabrera, J.-C, Vielle, M, Weidmann, N (2012). Assessment of acceptable Swiss post-2012 climate policies. Swiss Journal of Economics and Statistics, 148, 347-380

Sue Wing, I., Daenzer, K., Fisher-Vanden, K.\&C.K. (2011). Phoenix model documentation. Maryland: Joint Global Change Research Institute.

Swiss Federal Council (2013). Ordinance on the reduction of CO2 emissions. https://www.admin.ch/opc/en/classified-compilation/20120090/index. html. (last accessed on 21 Aug 2019).

Swiss Federal Council (2015a). Botschaft zum Verfassungsartikel über ein Klimaund Energielenkungssystem. BBI 2015, 7877-7924. https:/www.admin.ch/ opc/de/federal-gazette/2015/7877.pdf. (last accessed on 21 Aug 2019).

Swiss Federal Council (2015b). Verfassungsbestimmung über ein Klima- und Energielenkungssystem. Erläuternder Bericht zum Vorentwurf. https:// www.admin.ch/ch/d/gg/pc/documents/2625/Klima-undEnergielenkungssystem_Erl.-Bericht_de.pdf. (last accessed on 21 Aug 2019).

Swiss Federal Office of Energy (2017). Swiss Electricity Statistics. Bern: Swiss Federal Office of Energy.

van der, Werf, E (2007). Production functions for climate policy modeling: An empirical analysis. Energy Economics, 30, 2964-2979.

\section{Publisher's Note}

Springer Nature remains neutral with regard to jurisdictional claims in published maps and institutional affiliations.

\section{Submit your manuscript to a SpringerOpen ${ }^{\circ}$ journal and benefit from:}

- Convenient online submission

- Rigorous peer review

- Open access: articles freely available online

- High visibility within the field

- Retaining the copyright to your article

Submit your next manuscript at $\boldsymbol{s p r i n g e r o p e n . c o m ~}$ 